\title{
ANÁLISE DA COBERTURA ARBÓREA, FRAGMENTOS E CONEXÕES NO DISTRITO SÃO DOMINGOS (SÃO PAULO, BRASIL)
}

\author{
Léa Yamaguchi Dobbert ${ }^{1}$ e Sabrina Mieko Viana ${ }^{2}$ \\ 1 Arquiteta, doutoranda em Recursos Florestais pela Escola Superior de Agricultura "Luiz de Queiroz" \\ da Universidade de São Paulo, Piracicaba - SP. E-mail: Idobbert@usp.br \\ 2 Bióloga, doutoranda em Recursos Florestais pela Escola Superior de Agricultura "Luiz de Queiroz" \\ da Universidade de São Paulo, Piracicaba - SP. E-mail: smieko@usp.br
}

\section{Resumo}

O crescimento desordenado das áreas urbanas, decorrente da especulação imobiliária e da falta de um planejamento que leve em conta a dinâmica dos ecossistemas, é um dos maiores fatores que levam à fragmentação dos habitats naturais. Considerando a conectividade dos ambientes como importante fator para a melhoria da qualidade ambiental local ao promover o aumento da resiliência do ecossistema urbano, esta pesquisa teve como principal objetivo traçar um diagnóstico do uso e ocupação do solo, com ênfase na vegetação arbórea, assim como possibilidades de conexão entre fragmentos florestais, em especial os Parques Cidade de Toronto e São Domingos, no distrito de São Domingos, SP. O método utilizado baseou-se no uso de fotointerpretação, a partir de imagens de satélite do ano de 2007, onde foram detectadas áreas já existentes e potenciais para uso como redes de conexão entre as grandes áreas vegetadas no tecido urbano da área de estudo. Concluímos que a conexão entre os fragmentos existentes na área em estudo permitirá a construção de uma grande rede favorecendo considerável aumento da biodiversidade. Além disso, a metodologia aqui utilizada poderá ser adotada em projetos destinados ao traçado de estratégias para interligação da vegetação no tecido urbano.

Palavras-chave: Floresta urbana, Resiliência urbana, Conectividade, Corredores verdes 


\title{
ANALYSIS OF THE TREE COVER, FRAGMENTS AND CONNECTIONS IN SÃO DOMINGOS DISTRICT (SÃO PAULO, BRAZIL)
}

\begin{abstract}
The disorderly growth of urban areas, due to speculation and lack of planning that takes into account the dynamics of ecosystems, is one of the biggest factors that lead to fragmentation of natural habitats. In regard to the connectivity of the environment, an important factor for improving local environmental quality by promoting the increased resilience of the urban ecosystem, this study aimed to map out a diagnosis of the use and occupation of land, with an emphasis on vegetation, as well as possibilities connection between forest fragments, especially the City of Toronto and São Domingos Parks, in São Domingos District, SP. The method used in this research was based on photointerpretation, from satellite images of 2007, where we founded existing and potential areas for a network connection between the large vegetated areas in the urban fabric in our study area. We conclude that, the connection between the existing fragments will allow the construction of a large network favoring considerable increase biodiversity. Furthermore, the methodology used here can be adopted in projects aimed at tracing strategies for interconnection of vegetation in another urban areas.
\end{abstract}

Keywords: Urban forest, Urban resilience, Connectivity, Green corridors

\section{INTRODUÇÃO}

Os sistemas urbanos, classificados como heterotróficos por consumirem uma grande quantidade de recursos, superando em muito a capacidade de suporte do ambiente, são considerados como um dos principais responsáveis pela produção de uma grande pegada ecológica na matriz das paisagens agrícolas e naturais (ODUM e BARRET, 2008). A complexidade desses sistemas desafia aqueles que buscam compreendê-los e propor soluções para os graves problemas gerados pela própria lógica da ocupação do espaço urbano e a subversão das forças naturais (SPIRN, 1995).

As rápidas mudanças ocorridas na ocupação das cidades, quase sempre pensadas somente em nível local e voltadas para a estética, sem a preocupação ou o conhecimento sobre o funcionamento dos ecossistemas, são uma das grandes responsáveis 
pela perda de biodiversidade, fragmentação dos habitats e, por fim, pela diminuição ou perda de serviços ecossistêmicos (COLDING, 2007).

Em estudo sobre a melhoria da biodiversidade e da resiliência, Colding (2007) sugere o princípio da Complementação Ecológica do Uso do Solo (CEUS), no qual diferentes manchas verdes urbanas são agrupadas de forma a interagirem de forma sinérgica na promoção da biodiversidade. Com base nessa premissa, o alargamento dos habitats e a promoção da biodiversidade nas cidades poderiam ser alcançados com o arranjo espacial de vários tipos de manchas de verde urbano, próximas umas das outras, envolvendo, inclusive, o uso de quintais, jardins e ruas bem arborizadas, por conterem, muitas vezes, elevada biodiversidade.

A crescente urbanização e o consequente desaparecimento da vegetação nativa e de animais, aliados à crise de energia e à degradação do meio ambiente, levaram-nos a uma reflexão sobre as relações entre o homem e o meio ambiente: as relações ecológicas e os modos de sobrevivência (HOUGH, 1989). O traçado urbano do pós-guerra, ao criar paisagens que valorizam o automóvel em detrimento dos pedestres, demonstra a força mercantilista e o ideal das rodovias.

A desnaturalização da paisagem imposta por uma sociedade alienada dos valores ambientais contribuiu para a perda da singularidade da paisagem urbana, reduzindo sua história, tornando- a homogênea (MENDOZA, 2004). Nesse sentido, Michael Hough (1989) busca traçar um novo desenho da cidade visando torná-la mais saudável, na medida em que promove a convivência de maneira sustentável entre o ser humano e outras formas de vida.

A paisagem urbana, detentora de grande potencial econômico e tecnológico, continua a se render à pressão do mercado imobiliário. A falta de um planejamento que leve em conta a dinâmica dos ecossistemas representa um agravante para a fragmentação dos habitats naturais e a consequente perda de resiliência ambiental.

Nesse contexto, uma nova abordagem do planejamento ambiental, fundamentada na elaboração de cenários ambientais, é proposta por Franco (2001). Na perspectiva da autora, os cenários seriam a "projeção de uma situação futura, para o meio ambiente, tendo em vista a solução de um problema ou a melhora de uma condição presente indesejável ou insatisfatória." 
Faz-se necessário, portanto, que as cidades adotem outra forma de desenvolvimento com sustentabilidade visando à redução da crescente pressão exercida sobre seu espaço físico. Com o intuito de apresentar propostas para minimizar os efeitos nocivos da urbanização e sugerir conexões entre fragmentos de áreas verdes, Frischenbruder e Pelegrino (2006) realizaram uma pesquisa em algumas cidades da região sudeste do Brasil. Nesse estudo, os autores analisaram diversas áreas de acordo com seu potencial a fim de propor a implantação de greenways (caminhos verdes) em áreas urbanas como uma estratégia para promover a sustentabilidade do meio ambiente.

Alguns atributos chave dos greenways, apontados por Ahern (1995), referem-se à sua configuração linear, sua multifuncionalidade e ao seu potencial de sustentabilidade do meio ambiente na medida em que concilia o uso social da paisagem e a preservação do ambiente natural. Amorim (2011), em estudo realizado na cidade de São Paulo, com o auxilio de técnicas de geoprocessamento e sensoriamento remoto, também prioriza áreas potenciais para se tornarem corredores verdes, com intuito de melhorar a qualidade ambiental dentro da malha urbana.

É importante, quando se avaliam soluções para o espaço urbano, como a de implantação de caminhos verdes, destacar o papel da vegetação como um fator termorregulador do microclima, pois contribui de forma considerável no controle da radiação solar, na temperatura, na umidade do ar, na ação dos ventos e das chuvas e inclusive na meIhoria da qualidade do ar, ao amenizar sua poluição (MASCARÓ e MASCARÓ, 2009).

A preocupação com aspectos ambientais nas cidades é, sem dúvida, crescente. Entretanto a dificuldade de se estabelecerem critérios e padrões para avaliação de áreas verdes, de forma quanti-qualitativa, bem como de se avaliar a relação dessas áreas com sua população, observando sua distribuição em áreas urbanas, motiva a busca por novas formas de se analisar a qualidade do desenho urbano, inclusive da floresta urbana (SILVA FILHO, 2005).

O estudo aqui apresentado propõe um olhar para paisagem baseado no uso do solo, sua cobertura vegetal e os fenômenos da atividade humana que, de forma direta ou indireta, interferem no meio ambiente.

O principal objetivo desta pesquisa é analisar o espaço ocupado na região do bairro Parque São Domingos (São Paulo, Brasil) e traçar alternativas e soluções que prio- 
rizem a interligação de fragmentos florestais com uso de corredores verdes urbanos, em áreas potenciais de forma a melhorar a qualidade ambiental da região e a resiliência urbana.

\section{MATERIAIS E MÉTODOS}

\section{Área de estudo}

A área selecionada para este estudo está localizada na zona Noroeste da cidade de São Paulo e sua delimitação englobou parte da área dos bairros Parque São Domingos e City América, contido entre as microbacias do córrego Fiat Lux e Cintra, de forma a englobar dois importantes parques da região, o Cidade de Toronto e o São Domingos (Figuras 1 e 2). Ao todo a área analisada possui $2,58 \mathrm{~km}^{2}$.

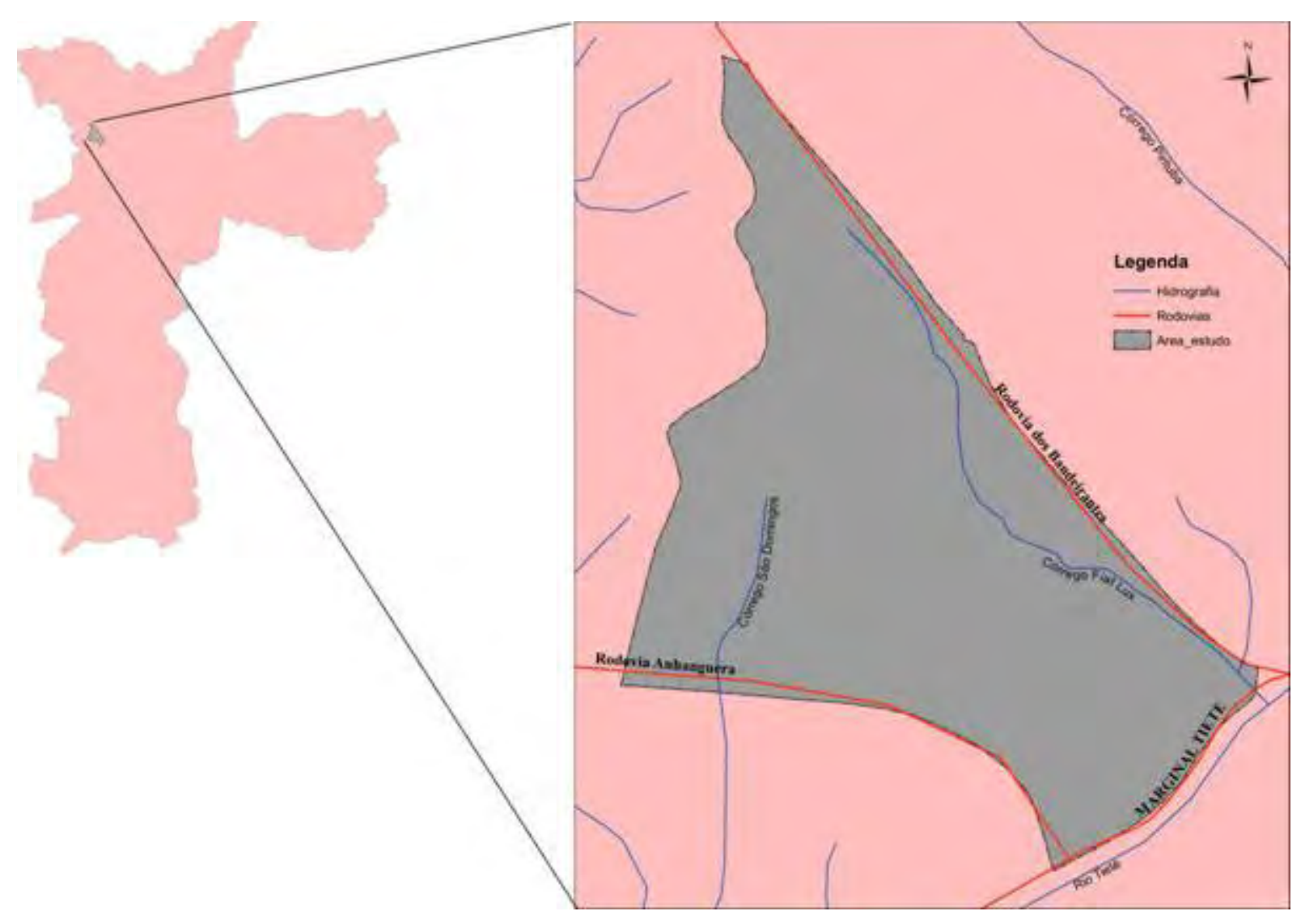

Figura 1: Área de estudo com indicação das principais vias do entorno e hidrografia. 


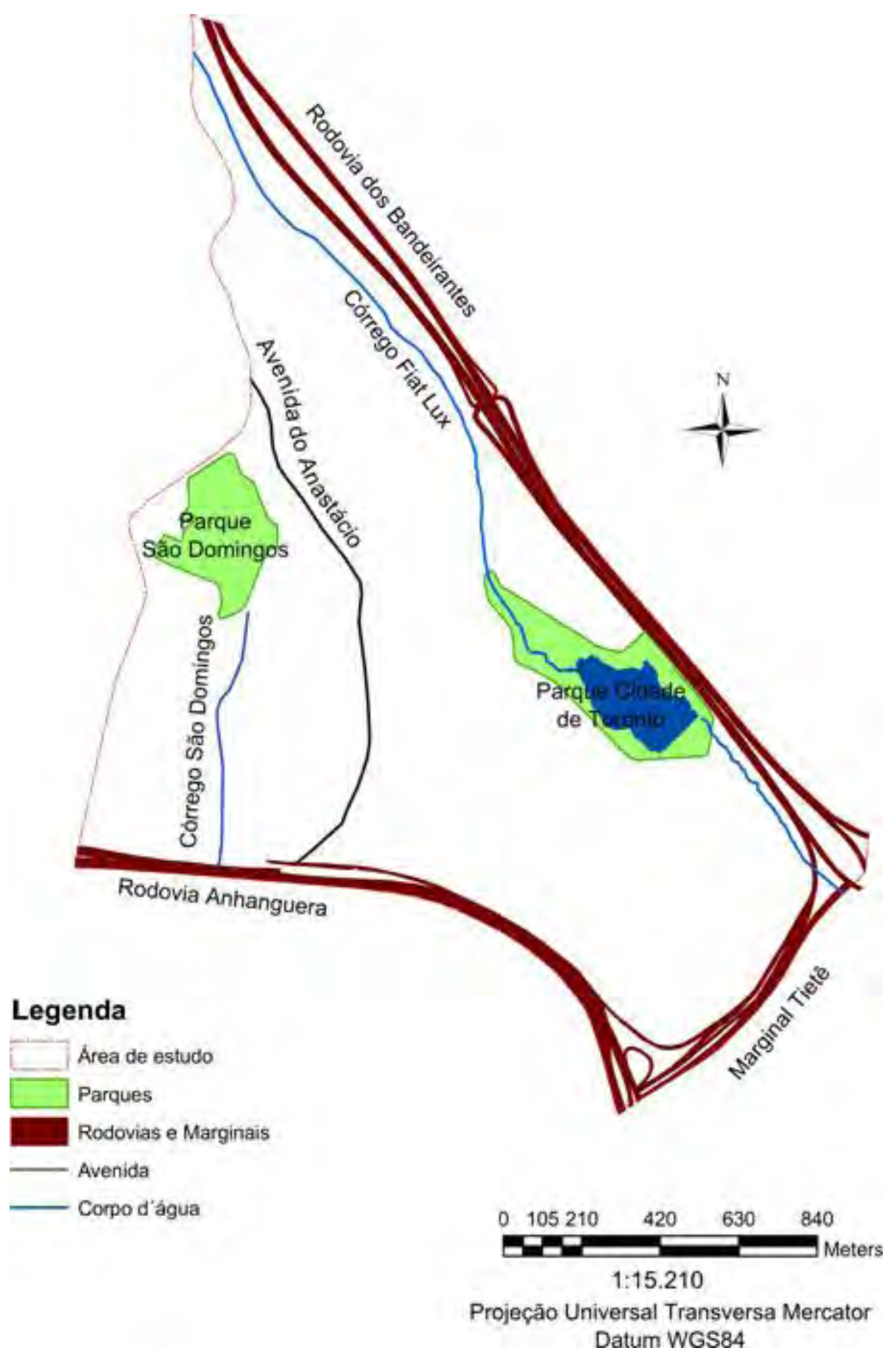

Figura 2: Área de estudo, com destaque para os parques Cidade de Toronto e São Domingos

O histórico de ocupação do distrito Parque São Domingos remonta a meados do século XIX, quando a área pertencia à fazenda do Coronel Anastácio de Freitas Trancoso, posteriormente comprada pelo Brigadeiro Rafael Tobias de Aguiar e sua esposa, a Marquesa de Santos. Já em 1917, a fazenda foi comprada pela empresa Armour frigoríficos e loteada a partir da década de 1950 pelas empresas Novo Mundo Investimentos e Cia. City (PMSP, 2012a). 
A região é caracterizada por ser compostas predominantemente de bairros residenciais de alto padrão (City América) em sua porção mais próxima ao Parque Cidade de Toronto, e de classe média nos mais próximos da área do Parque São Domingos e Avenida do Anastácio. Nesta última localização concentram-se as áreas de serviços e comércio da região. A proximidade com duas das principais saídas da capital rumo ao interior paulista, a rodovia dos Bandeirantes ao leste e Anhanguera ao sul/sudoeste é também pontos marcantes da área de estudo. A porção sudeste é limitada principalmente pelo Rio Tietê e suas vias marginais.

Os principais e maiores parques são o Cidade de Toronto, adjacente à rodovia dos Bandeirantes e o São Domingos ao centro da área de estudo. O primeiro possui aproximadamente $110.000 \mathrm{~m} 2$ e conforme Archangeletti (1993), seu projeto nasceu a partir de um programa de cooperação técnica entre profissionais brasileiros e canadenses, cujo projeto foi desenvolvido em 1989.

O parque está em terreno predominantemente inclinado, em uma área remanescente do loteamento City America, anteriormente degradada por atividades de mineração (Archangeletti, 1993). O projeto possui como característica marcante a construção de paisagens canadenses, com a inserção de espécies nativas daquele país e o wadding pool, típico de parques canadenses. A presença de áreas de brejo e seus bancos de macrófitas aquáticas emersas à montante e à jusante do lago alimentado pelo Córrego do Fiat Lux também, existentes antes da implantação do parque foram mantidos e desempenham importante papel na manutenção da fauna, especialmente de aves.

O parque São Domingos, cuja instalação data do ano de 1980, originou-se de uma área remanescente do plano de arruamento da região datado de 1953, que era utilizado pela população como campo de futebol (PMSP, 2012b). O parque é composto de $80.000 \mathrm{~m}^{2}$, composto por área de lazer com mesas, campo de futebol, vôlei, anfiteatros e bosque com espécies nativas e exóticas, referido como importante abrigo de avifauna (PMSP, 2012b).

\section{Análise do uso e ocupação do solo}

Para quantificação, qualificação e análise espacial dos componentes de uso e ocupação do solo realizou-se um mapeamento do uso e ocupação dos solos, na região selecionada, por meio de fotointerpretação (FITZ, 2008). Para tanto, foram utilizadas 
imagens de altíssima resolução espacial do software Google Earth Pro, advindas do satélite Geoeye-1, coletadas em dezembro de 2007. O trabalho de vetorização das diferentes classes de uso e ocupação do solo foi transferido e realizado em ambiente SIG, com escala de trabalho de 1:1.000, que eventualmente foi ampliada para localização de detalhes.

Uma vez que o foco deste trabalho é a vegetação e áreas com potencial para formação de corredores ou redes interligando entre maciços arbóreos, foram levantadas três classes de uso e ocupação do solo: copas de árvores, vegetação herbácea e solo exposto. Adicionalmente também foram demarcadas as principais vias da região (Rodovia dos Bandeirantes, Anhanguera e Avenida do Anastácio) e pela importância ecológica, também foram levantados os corpos d'água (lagos e córregos) e as áreas de brejo.

Para confecção dos mapas utilizados neste estudo foram utilizados como referência dados obtidos no Instituto Brasileiro de Geografia e Estatística - IBGE (2010) para os limites da área urbana e rodovias, enquanto os dados referentes à hidrografia fornecidos pela Agência Nacional de Águas - ANA (2010)

Também foram realizadas 3 visitas de campo em entre os meses de maio e abril de 2012 para registro fotográfico, análise do local e seus principais parques, assim como para a conferência dos alvos analisados nas imagens de satélite.

\section{RESULTADOS E DISCUSSÃO}

De toda área analisada, $0,44 \mathrm{~km}^{2}$ é coberta com copas de árvores, o que corresponde a $16,96 \%$ da região selecionada. As classes de vegetação herbácea e solo exposto ocupam respectivamente $0,78 \mathrm{~km}^{2}$ e $0,06 \mathrm{~km}^{2}$. As porcentagens obtidas são apresentadas na Figura 3. 


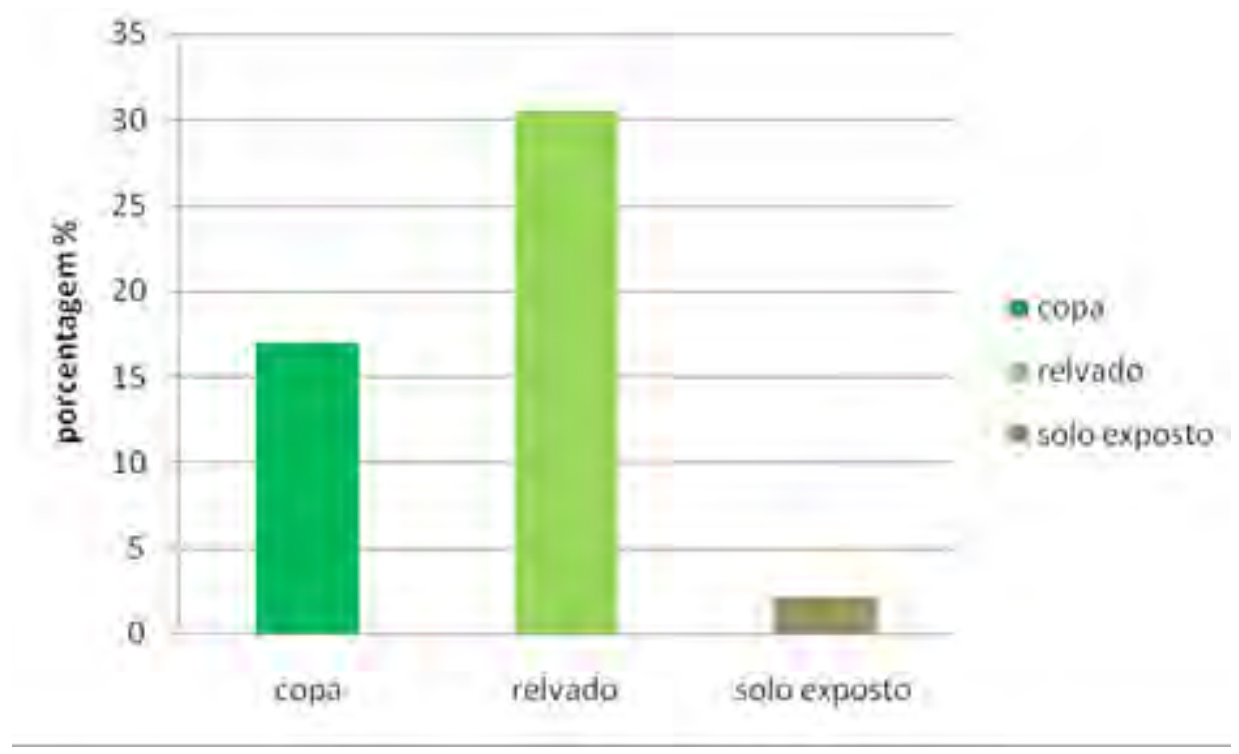

Figura 3: Porcentagens de ocupação das classes copa de árvores, relvado e solo exposto no trecho selecionado do Distrito Parque são Domingos.

Segundo Oke (1973 apud LOMBARDO, 1985) para se obter um balanço térmico adequado nas áreas urbanas, seria necessário no mínimo uma porcentagem de $30 \%$ de cobertura vegetal, valor este, superior ao encontrado neste estudo. Entretanto, alguns estudos chamam a atenção de que os valores "ideais" de cobertura arbórea devem ser ajustados de forma específica de cidade para cidade e deveriam ser estipulados somente após uma avaliação do que já existe na área, do tipo de ocupação (zona residencial, industrial, comercial) e até mesmo o tipo de vegetação pré-existente (NOWAK, 1996).

Por exemplo, para os Estados Unidos, a American Forests (2011) considera metas diferenciadas por zonas de ocupação (residenciais suburbanas, urbanas e distritos financeiros/comerciais) e também por região do país. Para as áreas metropolitanas do Mississippi e ao noroeste na costa do Pacífico, a maior porcentagem de cobertura é destinada para as áreas residenciais $(50 \%)$ sendo recomendada a porcentagem média na soma de todas as zonas em $40 \%$. Já para as áreas metropolitanas ao sudeste e ao oeste (regiões mais secas) a meta é estipulada em $25 \%$ na média geral e $35 \%$ para áreas residenciais. Para o Brasil ainda não são conhecidos estudos que avaliem esta necessidade, levando em conta as especificidades dos nossos biomas, bem distintos daqueles do Hemisfério Norte.

Além dos valores absolutos, a distribuição da cobertura arbórea e os arranjos dentro da área em questão também devem ser observados, pois isso interfere na qualidade 
da cobertura arbórea, se considerarmos, por exemplo, o grau de isolamento ou conectividade entre as manchas.

Na figura 4 é apresentado o mapa temático gerado pela fotointerpretação da área, onde são mostradas as classes de uso e ocupação de solo considerado neste estudo. Á partir desta imagem em conjunto com as visitas em campo, foram analisadas as áreas existentes e potenciais para ampliação da cobertura arbórea, além das possibilidades de conexão entre estas.

Com relação as áreas com potencial para ampliação da cobertura arbórea, verificou-se a porcentagem de $30,51 \%$ de áreas classificadas como "relvado" (vegetação não arbórea), com contribuição mais significativa de uma área de da antiga sede da Fazenda Anastácio e das faixas na borda da rodovia. Dentre as maiores manchas de vegetação arbórea, em área privada, destaca-se onde outrora funcionou a sede da empresa de fertilizantes Manah, com 56.700 m2 de cobertura arbórea (Figuras 5, 6 e 7).

Em visita a campo, contatou-se que a área da antiga Fazenda do Anastácio, com aproximadamente $140.000 \mathrm{~m} 2$, que contribui com aproximadamente $17,74 \%$ do total obtido para a classe relvado, está abandonada há longo período de tempo. O prédio existente hoje dentro da área foi construído na década de 1920 e já serviu como hospedaria, local de treinamento de cavalos e clube de lazer para funcionários do frigorífico Armour (PATARRA, 2012). Esta área apresenta grande potencial para requalificação, com incremento de vegetação nativa, promovendo a biodiversidade e o maior equilíbrio do ecossistema, e até mesmo como centro integrado para atividades culturais, educativas e de lazer para a população local, com ênfase na preservação de uma parte importante da história do bairro. Entretanto, segundo notícias veiculadas em fevereiro de 2012 (PATARRA, 2012), a construção ainda estaria em processo de tombamento, e a área onde a mesma se encontra, teria sido vendida a uma incorporadora americana, que tem planos erguer um shopping e vários prédios residenciais no terreno.

Observou-se também que na região delimitada entre a Avenida Anastácio e a rodovia dos Bandeirantes, que compreende boa parte do bairro de alto padrão City América, há maior quantidade de áreas permeáveis (relvado e solos expostos), provavelmente terrenos ainda aguardando valorização do mercado para posterior venda. Olhando a oeste da Avenida Anastácio, a quantidade de áreas livres é bem menor, assim como de áreas com cobertura arbórea significativa, à exceção do Parque São Domingos. 


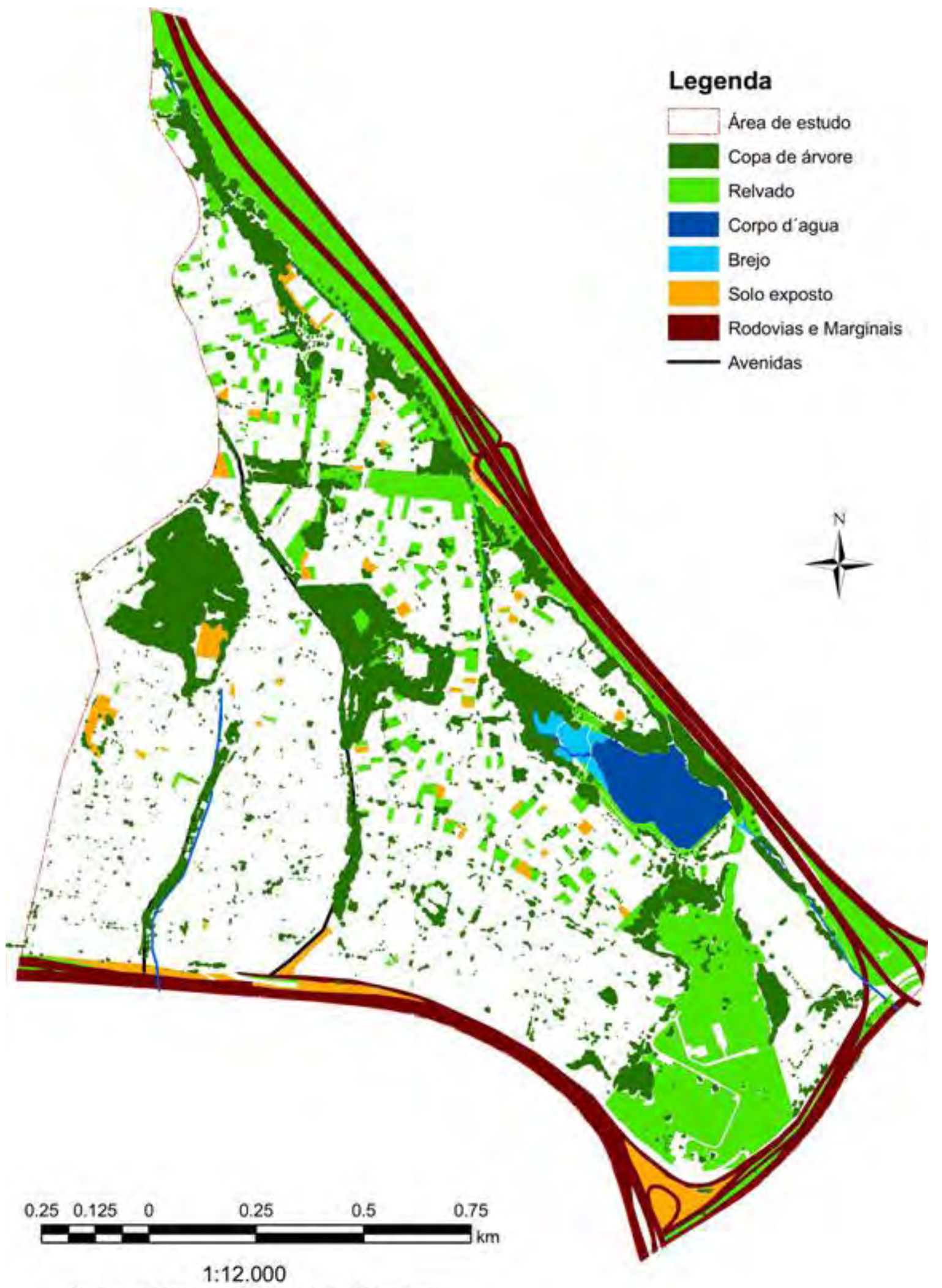

Projeção Universal Transversa Mercator Datum WGS84

Figura 4: Mapa temático do trecho estudado no Distrito São Domingos. 


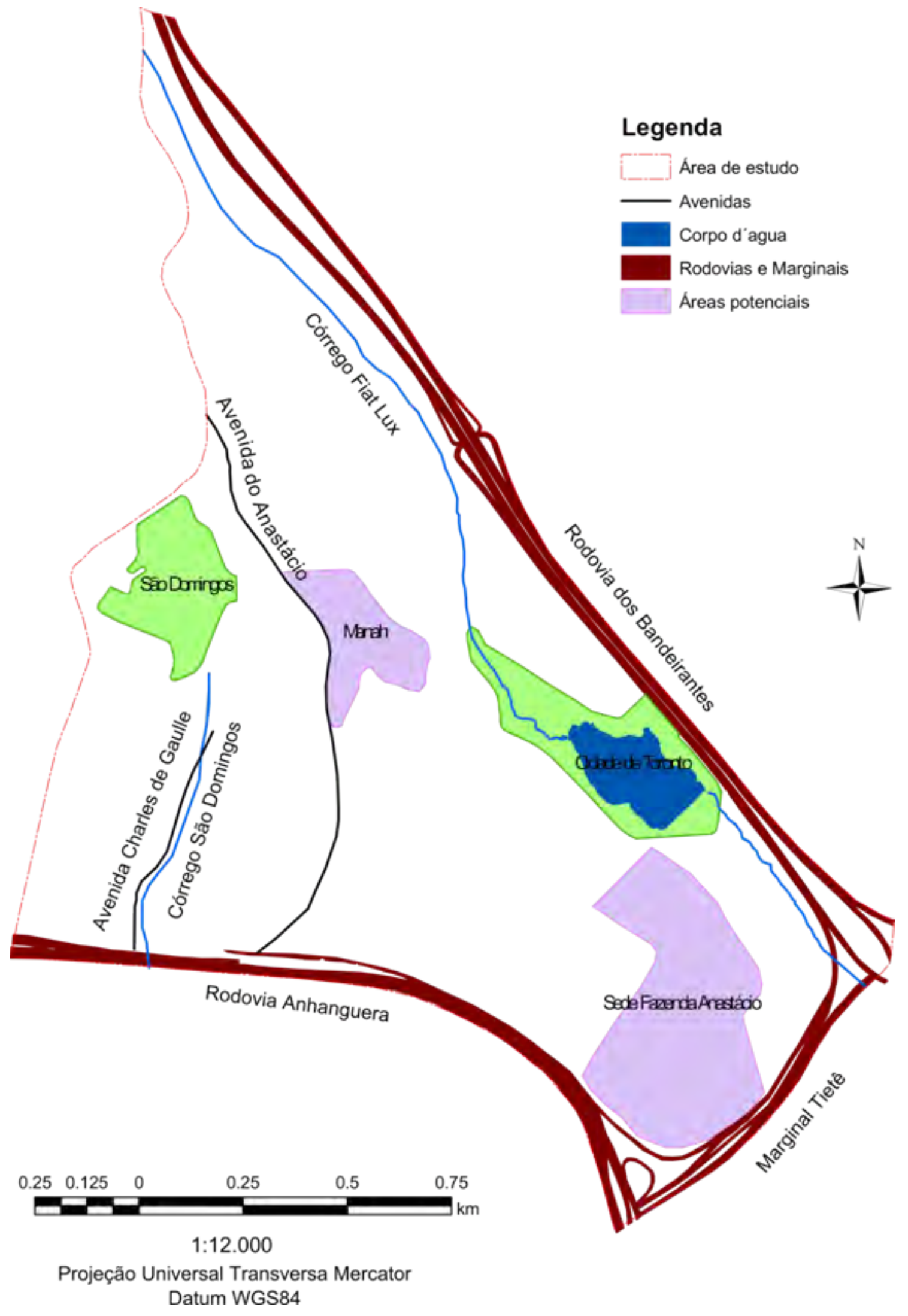

Figura 5: Localização das áreas da antiga sede da Fazenda Anastácio e antiga sede da empresa de fertilizantes Manah. 

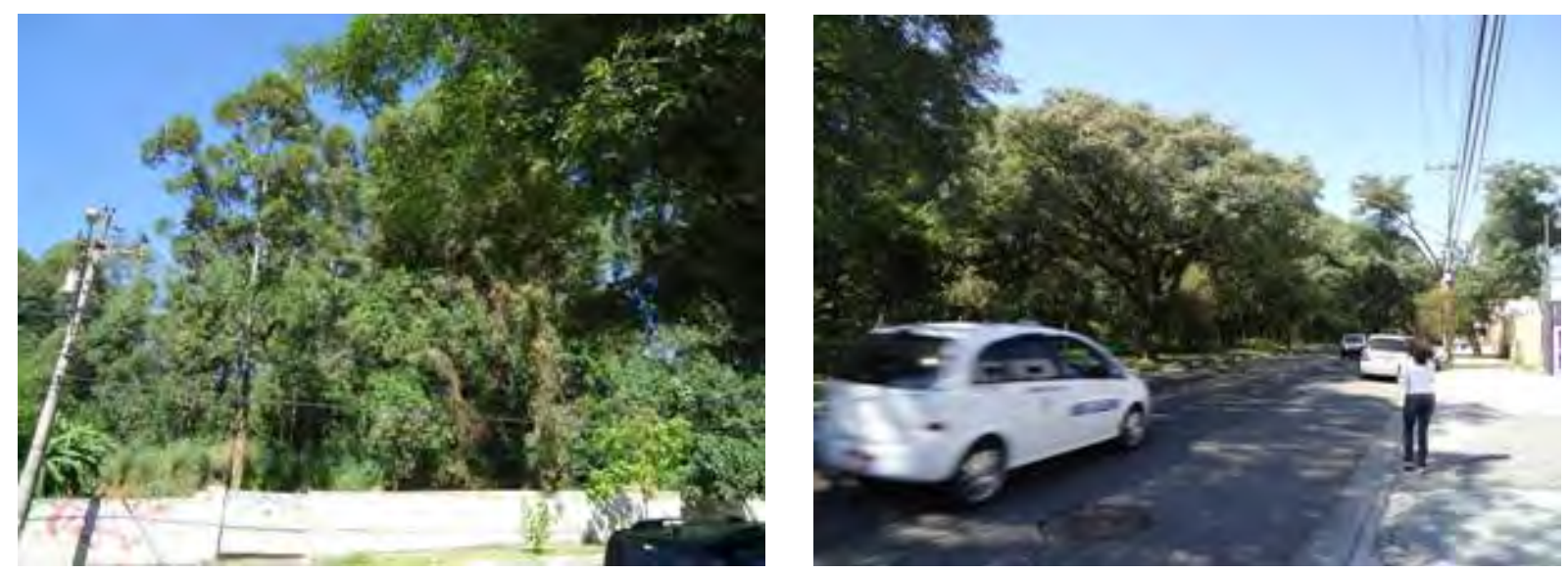

Figuras 6 e 7: Antiga sede da fazenda Anastácio, defronte o Parque Cidade de Toronto e trecho da área pertencente à antiga sede da empresa de fertilizantes Manah, em frente a Avenida Anastácio. Fonte: Sabrina Mieko Viana, 2012.

A análise do mapa temático também possibilitou verificar, ao menos na escala de trabalho desta fotointerpretação, que a quantidade de quintais com cobertura arbórea na região é escasso. Como forma de melhorar a cobertura arbórea e as possibilidades de formação de uma rede de corredores, poderiam ser estimulados os plantios, principalmente de espécies frutíferas, nestes quintais e jardins, levando em conta a diversidade da avifauna que já vive nas áreas dos Parques São Domingos e Cidade de Toronto. De acordo com Melles et al. (2003) o tamanho dos fragmentos observados dentro das áreas urbanas exercem grande influência na diversidade da avifauna, assim como a presença de fontes de água (rios, lagos, córregos) e a presença de quintais com espécies frutíferas, que acabam exercendo papel importante complementar para manutenção das aves e sua diversidade nas cidades. Além dos quintais, outra possibilidade a ser considerada são as pequenas praças existentes na área (figura 8), algumas já bem enriquecidas com vegetação e que poderiam ser multiplicadas em algumas das áreas vazias disponíveis, principalmente naquelas oeste da Avenida do Anastácio.

Outro ponto relevante da região em termos ecológicos é a presença de áreas alagáveis, brejos ou wetlands no entorno do lago do Parque Cidade de Toronto, cuja função ecológica demonstra-se como importante na biodiversidade local (BRAGION et al. 2010). Estas áreas úmidas são elementos enriquecedores do ambiente, e por se tratar de um ecótono, ou seja, uma região de interação entre um ambiente aquático e terrestre e que, portanto, abriga organismos das comunidades em sobreposição, mais aqueles que são restritos ao ambiente do ecótono (ESTEVES, 1998; ODUM e BARRET, 2008). 
Por fim, como regiões com maior potencial para interligação das manchas de vegetação arbórea, tanto das existentes como potenciais, está a arborização viária e os caminhos dos Córregos Fiat Lux e São Domingos, cujas principais possibilidades de corredores são traçadas na Figura 9.

Dentre os principais corredores já existentes identificados, estão aqueles na Avenida Anastácio, que praticamente já se conecta com a área da Manah, e da Avenida Charles de Gaulle que se aproxima mais do Parque São Domingos. Outro grande trecho seria a faixa que ladeia a Rodovia dos Bandeirantes, correspondente ao curso do Córrego Fiat Lux, que hoje é corre parte de seu trajeto em galerias ocultas sob grandes faixas de área verde, muitas com acesso dificultado ao público. Há ainda uma quarta possibilidade, que não está totalmente englobada na área desta pesquisa e que mereceria uma análise mais aprofundada por outros estudos, que é faixa de identificada na classe relvado, sob uma linha de alta tensão, facilmente identificada na região acima das áreas da Manah e Parque São Domingos. Entre estes grandes eixos sugere-se a extensão e interligação entre eles e as massas de vegetação por ruas menores, com ênfase na arborização viária e a presença nas laterais mais próximas de quintais e pequenas praças.

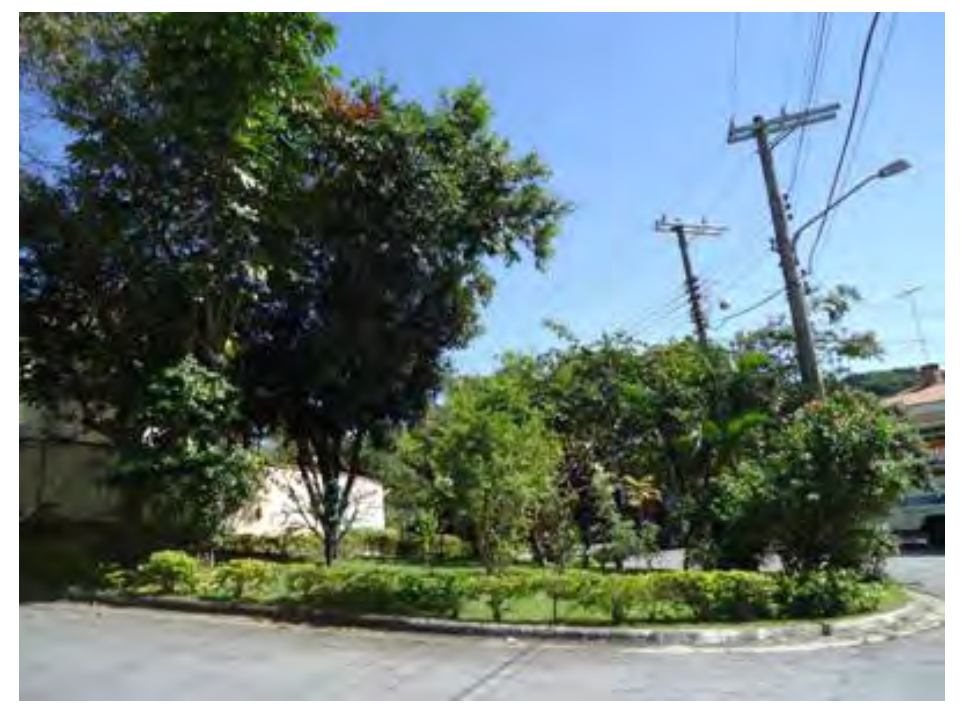

Figura 8: Exemplo de pequena praça no bairro City América, do lado leste da Avenida Anastácio. Fonte: Sabrina Mieko Viana, 2012. 


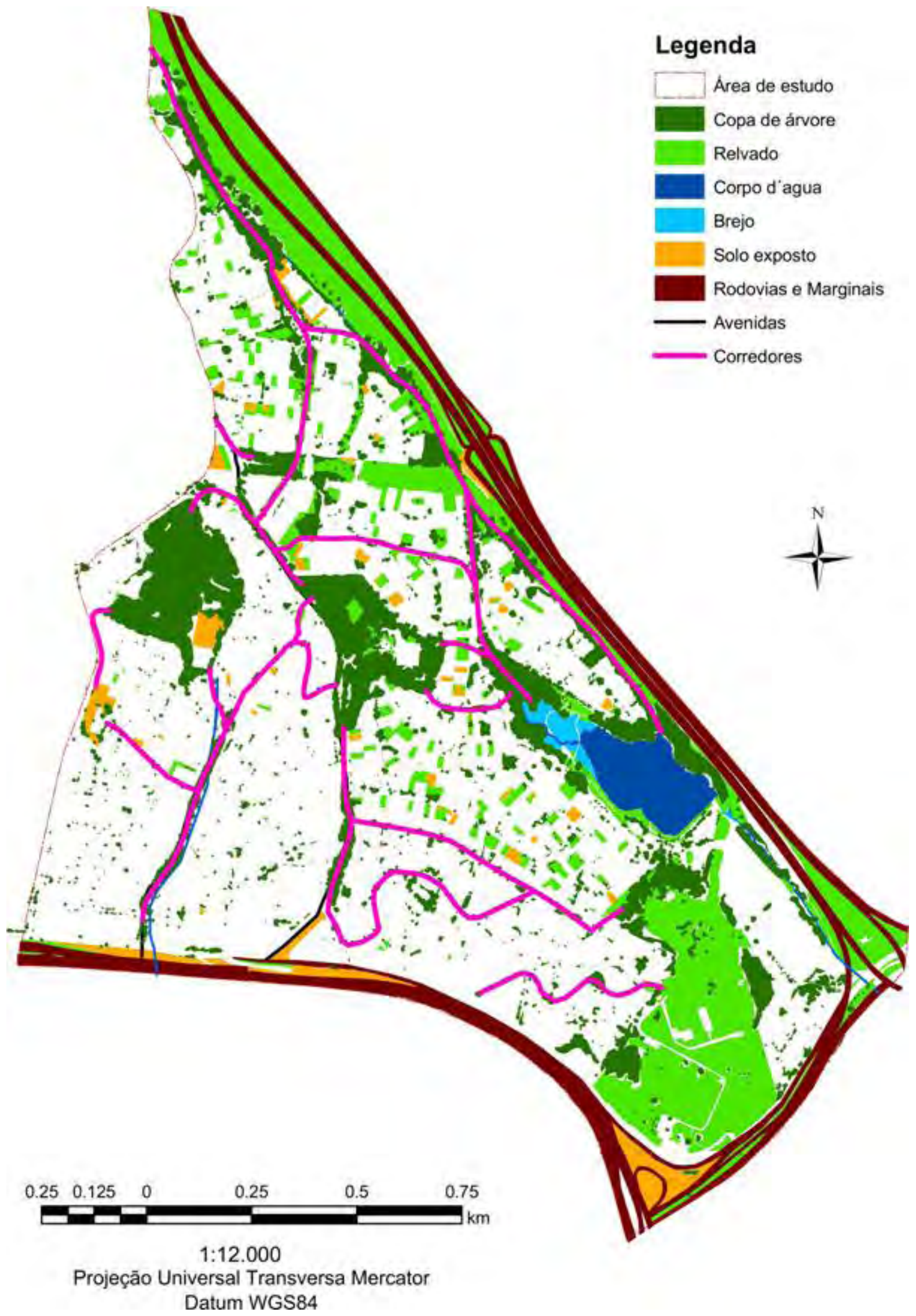

Figura 9: Traçado de áreas potenciais para se tornarem corredores verdes. 


\section{CONSIDERAÇÕES FINAIS}

A análise dos resultados indica que a região já possui uma cobertura arbórea razoável, comparada a outras regiões da cidade, muito em função da presença de dois parques próximos uns dos outros e a presença de áreas particulares, uma já com vegetação exuberante e bem desenvolvida e outra com potencial para tal. A configuração das calçadas no entrono, permite que a arborização viária seja privilegiada como área para formação de corredores interligando estes fragmentos entre si e ampliando assim algumas funções ecológicas locais, como ampliação de locais para abrigo e alimentação da fauna - em especial a de aves.

Dada a importância dos quintais e jardins arborizados, especialmente com espécies frutíferas, pode também servir como estratégia para ampliar algumas das funções dos corredores, aumentando assim a resiliência naquela área. Esta mesma estratégia também poderia ser adotada em pequenas praças, algumas já existentes no local estudado e também com a criação de mais algumas delas nos terrenos disponíveis, principalmente no lado oeste da Avenida do Anastácio onde há menor cobertura arbórea.

Com a conexão dos fragmentos existentes, aliada à arborização de áreas ociosas pode-se elevar consideravelmente a biodiversidade, construindo assim uma grande rede espalhada por todo bairro.

\section{REFERÊNCIAS}

AHERN, J. Greenways as a planning strategy. Landscape Urban Planning, v.33, p.131-155, 1995.

AGÊNCIA NACIONAL DE ÁGUAS (ANA). Hidroweb. Disponível em: <http://hidroweb. ana.gov.br>. Acesso em 10 dez. 2011.

AMERICAN FORESTS. Setting urban tree canopy goals. 2010. Disponível em: $<$ http://ftp.americanforests.org/resources/urbanforests/treedeficit.php>. Acesso em 05 ago. 2011.

ARCHANGELETTI, A.C.; TAKAHASHI, E.; BARNABÉ, H.R.; PIZA FILHO, P.T.; HON- 
DA, S.; O'CONNEL, P.; HUGHES, B.; YOUNG, D.; BARTON, D. Parque Cidade de Toronto In: PHILIPPI JR. (Coord.) A questão ambiental urbana: Cidade de São Paulo. Prefeitura Municipal de São Paulo/ Secretaria Municipal do Verde e Meio Ambiente, p.573-587, 1993.

BRAGION, I.V.; SILVA, P.C.; TONDI, F.M. Avifauna migratória do Parque Cidade de Toronto. Seminário de Áreas Verdes, 3, 2010. São Paulo. Anais. São Paulo: Secretaria Municipal do Verde e Meio Ambiente/Prefeitura Municipal de São Paulo. 2010, p.60-63.

COLDING, J. 'Ecological land-use complementation' for building resilience in urban ecosystems. Landscape and Urban Planning, v. 81, n.1-2, p.46-55, 2007

ESTEVES, F.A. Fundamentos de Limnologia. $2^{a}$ ed. Rio de Janeiro: Interciência, 602p., 1998.

FITZ, P.R. Geoprocessamento sem complicação. São Paulo: Oficina de Textos, 160p., 2008.

FRANCO, M. A. R, Planejamento ambiental para a cidade sustentável, $2^{\mathrm{a}}$ edição. São Paulo: Annablume Ed. 296p. 2001.

FRIESCHENBRUDER, M.T.M.; PELLEGRINO, P. Using greenways to reclaim nature in Brazilian cities, Landscape and Urban Planning, V. 76, p. 67-78, 2006.

HOUGH, M. City Form and Natural process. New York, Routledge, 280p, 1989.

INSTITUTO BRASILEIRO DE GEOGRAFIA E ESTATÍSTICA - IBGE. IBGE Cidades@. 2010. Disponível em: <http://www.ibge.gov.br/cidadesat >. Acesso em 06 jun. 2011.

MASCARÓ, L.; MASCARÓ, J. J. Ambiência urbana Ed. +4, Porto Alegre, 199p. 2009.

MELLES, S.; GLENN, S.; MATIN, K. Urban Bird Diversity and Landscape Complexity: Species-environment Associations Along a Multiscale Habitat Gradient. Ecology and Society, v.7, n.1, art. 5. 2003. Disponível em: <http://www.consecol.org/vol7/iss1/ art5/>. Acesso em 17 mai. 2012. 
NOWAK, D., ROWNTREE, R.A., MCPHERSON, E.G., SISINI, S.M., KERKMANN, E.R., STEVENS, J.C. Measuring and analyzing urban tree cover. Landscape and Urban Planning, v. 36, n.1, p. 49-57, 1996.

ODUM, E. P.; BARRET, G. W. Fundamentos de Ecologia. 5a edição. São Paulo: Cengage Learning, 612p., 2008.

PATARRA, I. Pedido de tombamento de casarão faz 21 anos. Diário de São Paulo. 2012. Disponível em: <http://www.diariosp.com.br/noticia/detalhe/13043/Pedido+de+t ombamento+de+Casarao+faz+21+anos> Acesso em 17 mai. 2012.

PREFEITURA MUNICIPAL DE SÃO PAULO - PMSP. Parque São Domingos 2012a. Disponível em: <http://www.prefeitura.sp.gov.br/cidade/secretarias/meio_ambiente/ parques/programacao/index.php? $p=5770>$ Acesso em 13/05/2012

PREFEITURA MUNICIPAL DE SÃO PAULO - PMSP. Histórico: conheça o histórico dos distritos de Pirituba/Jaraguá. 2012b. Disponível em: <http://www.prefeitura.sp.gov. br/cidade/secretarias/subprefeituras/pirituba_jaragua/historico/index. php? $\mathrm{p}=466>$ Acesso em 13/05/2012

SPIRN, A. W. 0 jardim de granito: A natureza no desenho da cidade. São Paulo: EDUSP, 345p, 1995. 